\title{
Tribo-corrosion of steel in artificial saliva
}

\author{
D. Holmes, S. Sharifi and M.M. Stack* \\ Department of Mechanical and Aerospace Engineering \\ University of Strathclyde \\ James Weir Building \\ 75 Montrose St. \\ Glasgow \\ G1 1XJ
}

*Corresponding author. E-mail address: margaret.stack@strath.ac.uk

\section{Introduction}

Tribology has many applications in the field of dentistry as the oral biomechanical functions lead to tribological movement of teeth, restorations and implants occurring in the mouth [1]. Hence, tribology plays an important role in the assessment of the performance of foreign fixed materials in the oral cavity and their longevity whether the material is a conventional metal or a more complex ceramic. Also, chemical reactions with food, interactions with the food particles, resulting forces of chewing itself, all combine to act on such materials [2]. Therefore, it is important to evaluate how a material would react to these processes to ensure the longevity of the material and to avoid adverse reactions within the mouth causing decay.

The corrosion resistance and mechanical properties of stainless steels make them a suitable material for use in medical applications, including dental purposes and orthopaedic treatments. The main quality of stainless steel is its resistance to corrosion, which can vary depending on the grade of stainless steel used but the formation of a passive chromium oxide film (passivation) can protect the material [3], [4]. The addition of chromium and nickel to steel (generally 18 and 8 wt\% respectively) creates an austenitic structure. Ultimate tensile strength of austenitic steel is a desirable property for medical purposes. 316L grade stainless steel, using the American Iron and Steel Institute (AISI) classification system, is a common bio-compatible austenitic stainless steel. The designation of 316L indicates a lower carbon content, less than $0.03 \%$, compared to 316 grade which contains $0.08 \%$ carbon. $316 \mathrm{~L}$ stainless steel is protected from grain boundary carbide precipitation, known as sensitisation. Applications of $316 \mathrm{~L}$ stainless steel include food preparation equipment, pharmaceuticals, marine, architectural and medical applications including dental implants. The most common usage of $316 \mathrm{~L}$ grade stainless steel is as a material for orthopaedic brackets. Although duplex steels are increasingly being used instead of austenitic steels, the use of austenitic steels is 
still widespread [5]-[7]. In dentistry, selection of the dental materials generally comes down to the personal preference of the dentist. However, factors such as ease of handling, availability and cost are important factors in the selection process [8]. The durability and low cost of stainless steel makes it an appropriate choice for use in dental crowns, especially where the use of other materials is not economically viable. As of 2005, the British Society of Paediatric Dentistry (BSPD) recommended the use of stainless steel (pre-formed) crowns for the restoration of primary molars with multi-surface lesions, extensive caries (cavities) and those where pulpal treatment has been performed [9]. Steel alloys have also been used for the construction of orthodontic instruments, wires and denture bases and dental implants. The reported issue with alloy dental implants is the release of elements to the adjacent tissues as the alloys that are subject to abrasion due to opposing occlusion or restorations may release higher levels of elements. Also, in rare cases it may result in allergic reactions in the body. This problem has reduced the use of stainless steel as implants in developed countries although it can be addressed by deposition of a noble metal coating. However, the element release of non-implanted dental alloys is little even over long periods of time [8], [10]. Of course, such phenomenon depends of the surrounding medium properties and the present solution, too. A study by Karimi [11] showed that in bovine serum albumin (BSA) the material loss rate of 316L under tribocorrosive conditions is higher compared to CoCrMo and Ti-6Al-4V; however, it was due to presence of a sort of protein in the environment and cannot be generalised to oral cavity. Generally, the material loss rate of $316 \mathrm{~L}$ due to mechanical wear under tribo-corrosive conditions is significantly higher than the corrosive wear [3].

In the oral cavity, saliva, produced by the salivary glands, acts as a lubricant and aids mastication by helping food transportation and provides the necessary lubrication required between the hard and soft tooth tissue. Saliva reduces the amount of wear that takes place in the oral cavity, which extends the lifespan of both teeth and dental implants and reduces the need for intervention [12]. There are many components of real saliva that serve various complex biological processes, and hence it is difficult to completely produce artificial saliva that matches the composition of saliva fully. However for experimental purposes, the artificial saliva produced is adequate if it interacts with the metal sample in a similar way to which real saliva would [13]. Wang et al. looked at the friction and wear behaviours of dental ceramics against natural tooth enamel using Fusayama solution [14]. Li et al. explored wear behaviour of human teeth in dry and artificial saliva conditions which explored the frictional behaviour of human teeth and titanium [15]. Ziskind et al. studied amalgam type, adhesive system, and storage period as influencing factors on micro-leakage of amalgam restorations [16]. Other studies have examined corrosion effects of materials in this substance [17]-[21], however there appears to be few micro-abrasion-corrosion tests have been carried out with artificial saliva.

The purpose of this work is to study the wear mechanisms of $316 \mathrm{~L}$ grade stainless steel as an orthodontic material in artificial saliva using a micro-abrasion-corrosion apparatus. Also, microabrasion maps are generated based on the results the effects of exposure time and applied load.

\section{Materials and methodology}

Micro-abrasion-corrosion tests on the effects of applied load and exposure time were carried out. The results produced were in the form of the amount of wear that has taken place, found from the wear scar volume. These results were represented as wear maps, showing the conditions of the highest and lowest amounts of wear occur. 


\subsection{Test samples}

The composition of $316 \mathrm{~L}$ grade stainless steel can be seen in table 1 [22]. The samples were made from a purchased standard 316L AISI stainless steel square bar in the Department of Mechanical and Aerospace Engineering, University of Strathclyde, by cutting them to $30 \mathrm{~mm}$ in length and breadth and the thickness after machining and surface finish was $3 \mathrm{~mm}$. This specific size was in order to fit the samples securely into the test rig. The surface finish $\left(R_{a}\right)$ was $3 \mu \mathrm{m}$ and cleaned with diluted methanol. It should be noted that no surface coating was applied to the material and the samples were tested as a bulk material. The mechanical properties of the test samples are shown in table 2 .

\begin{tabular}{ccccccccccc}
\hline \multicolumn{10}{c}{ Chemical compositions of the test samples (wt. \%) } \\
\hline $\mathbf{C}$ & $\mathbf{M n}$ & $\mathbf{S i}$ & $\mathbf{P}$ & $\mathbf{S}$ & $\mathbf{C r}$ & $\mathbf{M o}$ & $\mathbf{N i}$ & $\mathbf{N}$ & $\mathrm{Fe}$ \\
$0.03 \max$ & $2.00 \max$ & $0.75 \max$ & $0.03 \max$ & $0.03 \max$ & $17-20$ & $2-4$ & $12-14$ & 0.1 & Bal. \\
\hline
\end{tabular}

Table 1- Chemical composition of the test samples

\begin{tabular}{cccc}
\hline Material Property & 316L & UHMWPE & Alumina \\
\hline Density $\left(\mathrm{kg} / \mathrm{m}^{\mathbf{3}}\right.$ ) & 8000 & $931-935$ & 3800 \\
Young's Modulus (GPa) & 192 & 0.689 & 351 \\
Hardness (Vickers) & 195 & 541 & 3.5 \\
$\begin{array}{c}\text { Fracture Toughness } \\
\left(\mathrm{MPa} / \mathrm{m}^{\mathbf{1 / 2}}\right)\end{array}$ & 100 & $3.5-6$ & 3.5 \\
\hline
\end{tabular}

Table 2 - The mechanical properties of the test materials [23]-[27]

\subsection{Test slurry}

The abrasive slurry was formed using artificial saliva mixed with abrasive particles. The produced artificial saliva for this set of experiments is known as Fusayama solution. This solution was selected for use in these tests because of its established use within dental material testing. The reactions of different alloys to the electrolytes found within this solution are considered resembling those in natural saliva [14], [28]. The $\mathrm{pH}$ of this solution can range approximately between values of 5 and 7 [20]. The pH of the slurry used in this work was 5.7. The chemical composition of the produced artificial saliva can be seen in table 3 .

\begin{tabular}{ccccccc}
\hline \multicolumn{7}{c}{ Artificial saliva composition (g/l) } \\
\hline $\mathrm{NaCl}$ & $\mathrm{KCl}$ & $\mathrm{CaCl}_{2} \cdot \mathbf{2} \mathrm{H}_{2} \mathrm{O}$ & $\mathrm{NaH}_{2} \mathrm{PO}_{4} \cdot 2 \mathrm{H}_{2} \mathrm{O}$ & $\mathrm{Na}_{2} \mathrm{~S} .9 \mathrm{H}_{2} \mathrm{O}$ & Urea & Distilled water \\
0.4 & 0.4 & 0.795 & 0.78 & 0.005 & 1 & 1000 \\
\hline
\end{tabular}


Slurries containing abrasive particles can be used in order to simulate food bolus within the mouth during mastication [2]. For these experiments calcined alumina particles (Logitech, UK), with the concentration of $30 \mathrm{gg}^{-1}$, were used. A range of particles have been used to simulate food bolus [29]. In the above case, the hardness of the alumina particles ( 9 in Moh's scale) is much higher than that of $316 \mathrm{~L}$ stainless steel. If the sample and abrasive particle are closer in terms of hardness value, the situation is known as soft abrasion, the alterations of the hardness value of the abrasive particles used can significantly affect the wear rate [30]. Also, softer particles degrade in such conditions which are not suitable for the current study. The hardness of alumina makes them an appropriate choice to create severe conditions and assess the longevity of the test materials [31]. The flatness of the alumina particles can also spread the load effectively at the interface [32]. The particles had an average size of $9 \mu \mathrm{m}$. The mechanical properties of the particles are presented in Table 2 . In order to avoid particles flocculation, the slurry supplied to the apparatus was kept agitated using a small magnetic stirrer at the bottom of the reservoir.

\subsection{Test apparatus}

A ball cratering wear test apparatus, TE-66 Micro-Scale Abrasion Tester (Plint TE-66, Phoenix Tribology, Reading, UK), was used to provide the abrasion system. In this apparatus a rotating ball is clamped in split drive shaft which allows the ball to be removed and replaced conveniently. The ball rotates against the test samples and the slurry is dripped into the contact between the ball and the sample [33]. The sample to be examined is held on a platform against the rotating ball on a pivoted L-shaped arm. The desired normal force is provided using

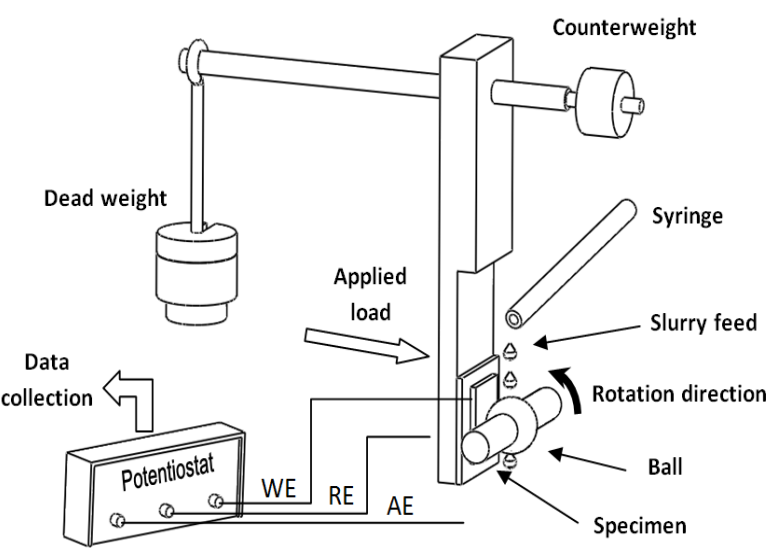

Figure 1 - The test rig dead weights hanging from the horizontal lever [34]. A diagram of the test rig used is shown in Figure 1.

One of the co-axial shafts is driven by a variable speed DC motor which rotates the ball using friction. In turn, the ball rotates the second co-axial shaft which is connected to a peristaltic pump which supplies the slurry to the interface through a syringe. The cratering balls used for these experiments were ultrahigh molecular weight polyethylene (UHMWPE), (K-mac Plastics, Michigan, USA), which possess high chemical resistance, smooth molecular profile, high mechanical toughness and wear resistance [35], [36]. Also, this material can provide the coefficient of friction of 0.05 to 0.08 in wet conditions [26]. This can create a condition where the counter-face body only provides a form of foundation for the particles to see the effects of the abrasive particles on the test samples. The diameter of the balls was $31.75 \mathrm{~mm}$.

The electrochemical tests were conducted in a corrosion cell where a potentiostat was set up which created a circuit with the rig via a Working Electrode (WE) an Auxiliary Electrode (AE) and a Reference Electrode (RE). The potentiostat, ACM Instruments UK, was connected to Core Running/Sequencer software on a computer allowing polarisation curves to be created. The WE was connected to the back of the sample. A saturated calomel electrode (SCE) was used as the RE making 
contact with the circuit via a capillary tube. For the AE a Platinised-Titanium (Pt-Ti) mesh was located within the non-metallic (non-conductive) slurry collection tray underneath the contact point. The platform which held the sample was also made from a non-conductive polymer to ensure that the sample was insulated away from at the point of contact $\left(A=1 \mathrm{~cm}^{2}\right)$. The point of contact (and therefore the wear scar) was immersed throughout the experiment as the peristaltic pump coated the sample in the corrosive slurry which was collected underneath. The slurry itself was part of a circuit as it constantly flowed between the non-conductive collection tray and an external container via flexible tubing. After the initial stabilisation, DC polarisation scans were performed at a sweep rate of $50 \mathrm{mV} \mathrm{min}^{-1}$ from -1 to $0.5 \mathrm{~V}$. It should be noted that the experiments were conducted in a non-de-aerated condition.

\subsection{Test method}

Various parameters of the test can be altered such as exposure time, loading force and the sliding velocity. In this case sliding velocity was kept constant at $150 \mathrm{rpm}$. Tests were carried out with loads ranging from $0.5 \mathrm{~N}$ to $4 \mathrm{~N}$ and test durations of between 0.5 hour and 3 hours. The effects of altering these parameters on the wear mechanisms produced have been examined in previous work [37], [38]. Table 4 shows the list of parameters.

\begin{tabular}{cc}
\hline \multicolumn{2}{c}{ Test parameters } \\
\hline Test duration (hrs) & $0.5,1,2$ and 3 \\
Applied load $(\mathrm{N})$ & $0.5,1,2$ and 4 \\
Sliding velocity $(\mathrm{m} / \mathrm{s})$ & $0.3\left(897.75 \mathrm{mh}^{-1}\right)$ \\
\hline
\end{tabular}

Table 4 - Test parameters

After conducting the experiments, scanning electron microscopy (SEM), S-3700N Tungsten Filament SEM (Hitachi High-Technologies, Europe), was used to examine the wear scars. The detailed pictures of the wear scars were produced showing the different wear regimes that have taken place and the size of the wear scars were measured through the SEM.

\section{Results}

\subsection{Volume loss}

As the test samples are monolithic (no perforation takes place) and the shapes of the craters are conformal to the shape of the ball, the volume loss can be calculated using Equation 1:

$V=\frac{\pi b^{4}}{64 R}$

where $V$ is the scar volume, $b$ is the scar diameter and $R$ is the cratering ball radius where $b<<R$. The diameter of each wear scar was measured during the SEM analysis.

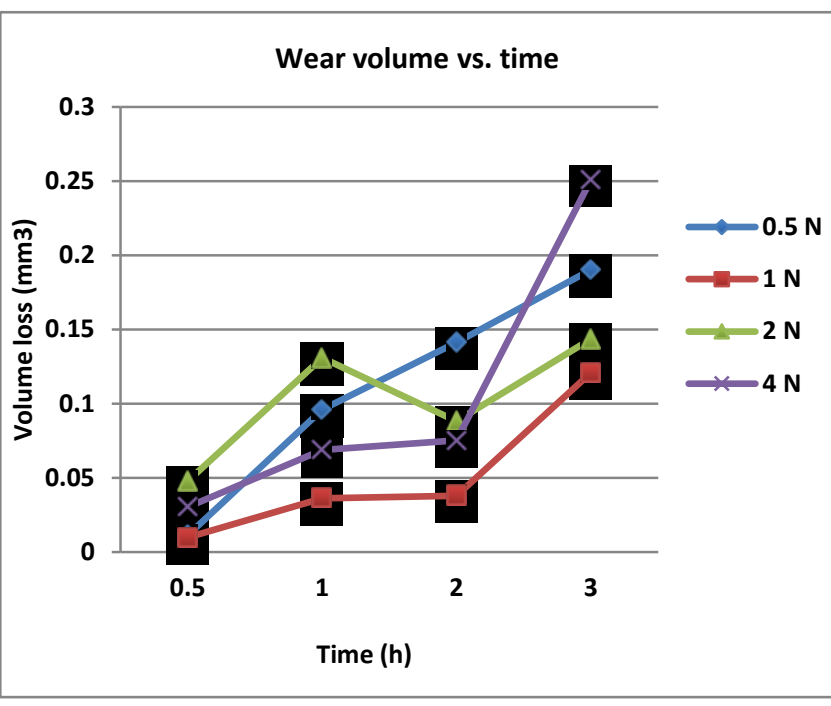

Figure 2 - Volume loss results 
Figure 2 shows the volume loss results for different loads over the test durations. The final magnitude of the volume loss for each load has increased comparing to the initial value, although a linear approach cannot be clearly seen. In order to consider the effects of the particles on the wear mechanisms, especially corrosive wear, the tests were conducted for $0.5 \mathrm{~h}$ for each load without particles. Figure 3 compares the volume loss results of $0.5 \mathrm{~h}$ test with particles to the tests without particles.

Figure 3 - Volume loss results for $0.5 \mathrm{~N}$ tests with and without particles

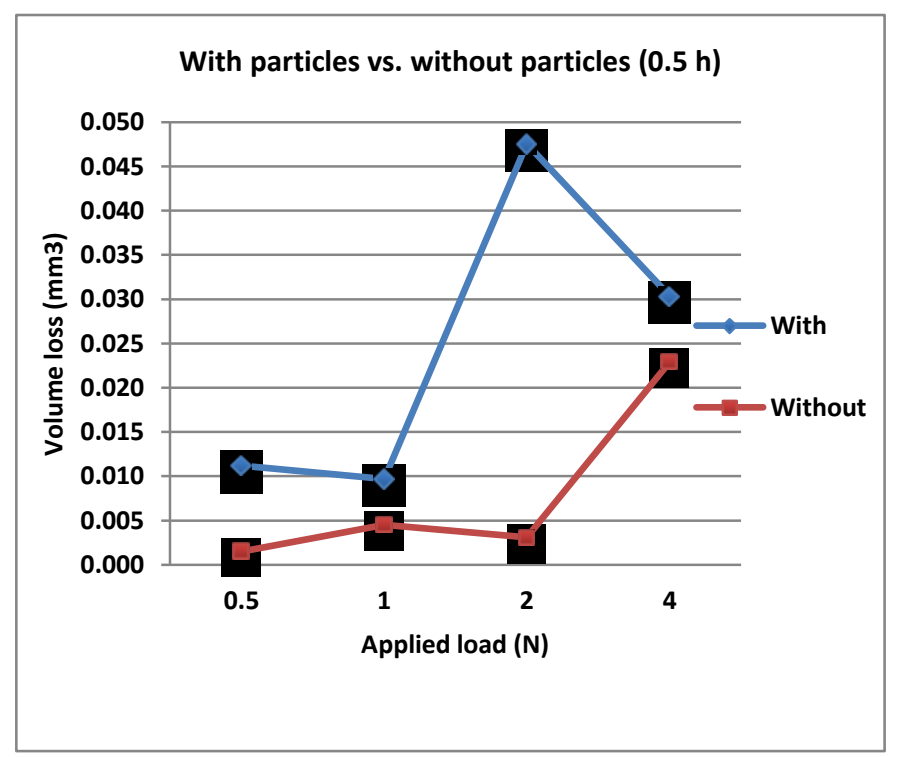

\subsection{Polarisation tests}

The potentiodynamic polarisation scans were performed to investigate the in vitro corrosion behaviour of $316 \mathrm{~L}$ stainless steel in the artificial saliva with and without abrasive particles. Figure 4 illustrates the difference that the presence of particles can make to the performance of $316 \mathrm{~L}$ under similar applied loads. It indicates that for conditions without particles, Fig. 4(a), the corrosion potential was approximately similar for all applied loads and there was little evidence of an increase in corrosion current with altering load. The presence of the particles reduces the corrosion potential for all the applied loads. Also, the amplitude of the corrosion currents increases for the range of the loads tested. Although 316L stainless steel should be ideally immune to sensitisation, the irregularities in the in the anodic polarisation scan in Fig. 4(b) can suggest that abrasive particles (an aggressive environment) can cause the precipitation of the chromium carbides at the grain boundaries. As the chromium depleted zones are as corrosion resistant as the bulk 316L, preferential corrosion along the grain boundaries may occur. Plastic deformation is significant factor in determining the extent of the occurrence of sensitisation and clearly, the presence of the abrasive particles inclines the amount of the volume loss according to the results of the previous section [39]. 


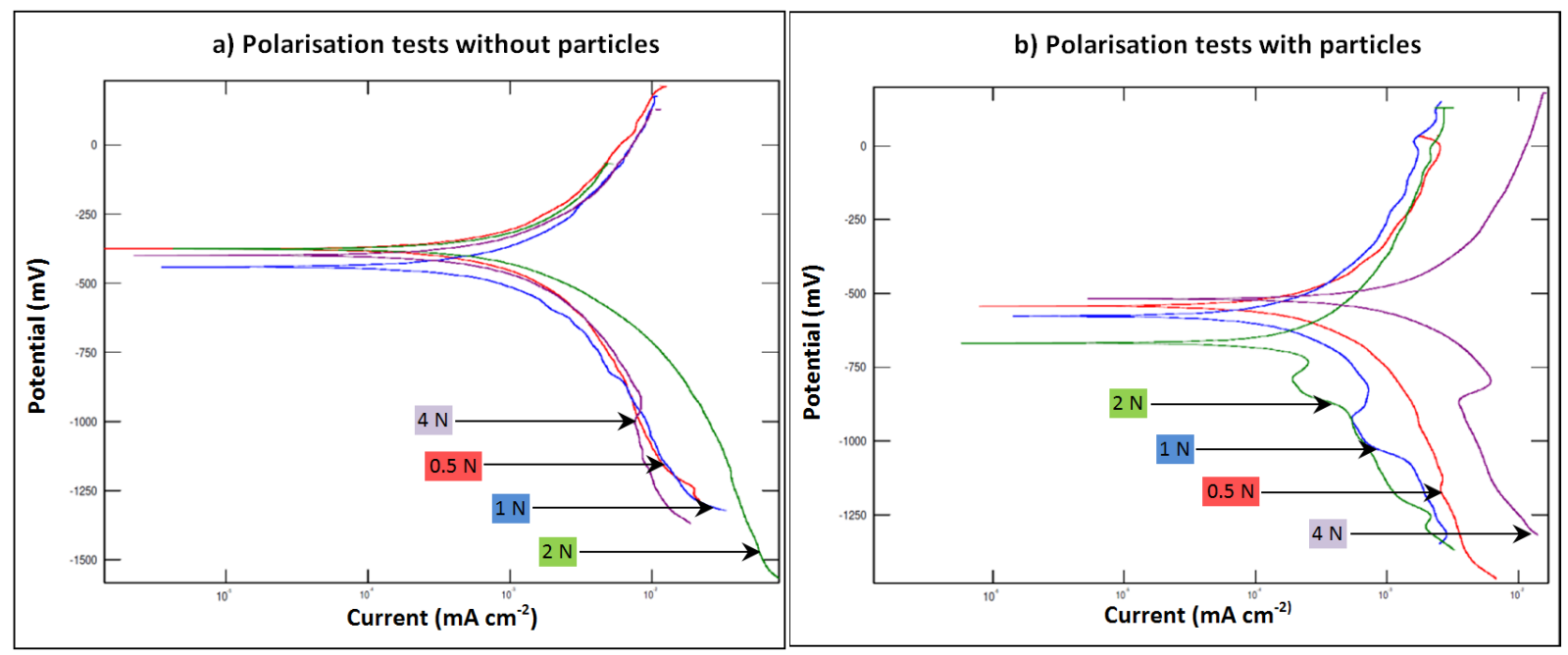

Figure 4 - Polarisation test results for $0.5 \mathrm{~h}$ tests a) without and b) with particles for different loads

\subsection{SEM results}

The SEM was used to identify the wear mechanisms occurred in the experiments. The terminology describing the wear mechanisms will be explained using common definitions; however, the main terms used (two-body and three-body wear) have been described as ambiguous and contradictory and there have been various proposals to redefine these terms [37], [40]. Despite this, the use of the terms is still widespread and the definitions described here are the generally accepted definitions.

Figure 5 shows how the change in applied load can affect the type of wear that is produced and how at some intermediate load a transition must take place between two-body and three-body wear. Figure $5 \mathrm{a}$ is the very smooth wear scar produced after 3 hours with $0.5 \mathrm{~N}$ of applied load. Despite the low load, the wear volume is relatively high compared to the other 3 hour tests. This wear scar has no clear directional deformation suggesting the presence of three body wear; this is consistent with what is expected in low load situations [37]. In figure $5 \mathrm{~b}$, the $0.5 \mathrm{~N}$ wear scars are contrasted by the wear scar produced by the 3 hour, $4 \mathrm{~N}$ applied load test which produced a heavily deformed wear scar with clear directional grooving. This indicates that two-body wear has taken place. Figure $5 c, 3$ hours under $2 \mathrm{~N}$ applied load, exhibits a magnification of how the mechanism transitions have begun by increasing the load as the higher loads tend to cause two-body grooving. Figure $5 \mathrm{~d}$ also shows a higher magnification of 3 hour, $4 \mathrm{~N}$ applied load wear scar where the entrainment of the abrasive particles have taken place. Particle entrainments can cause an increase of the wear rate as more particles become entrained further entrainment happens more quickly, resulting in higher wear rates [31]. However, the rate of entrainment can vary under different applied loads depending on the possibility of ridge formations [41]. 

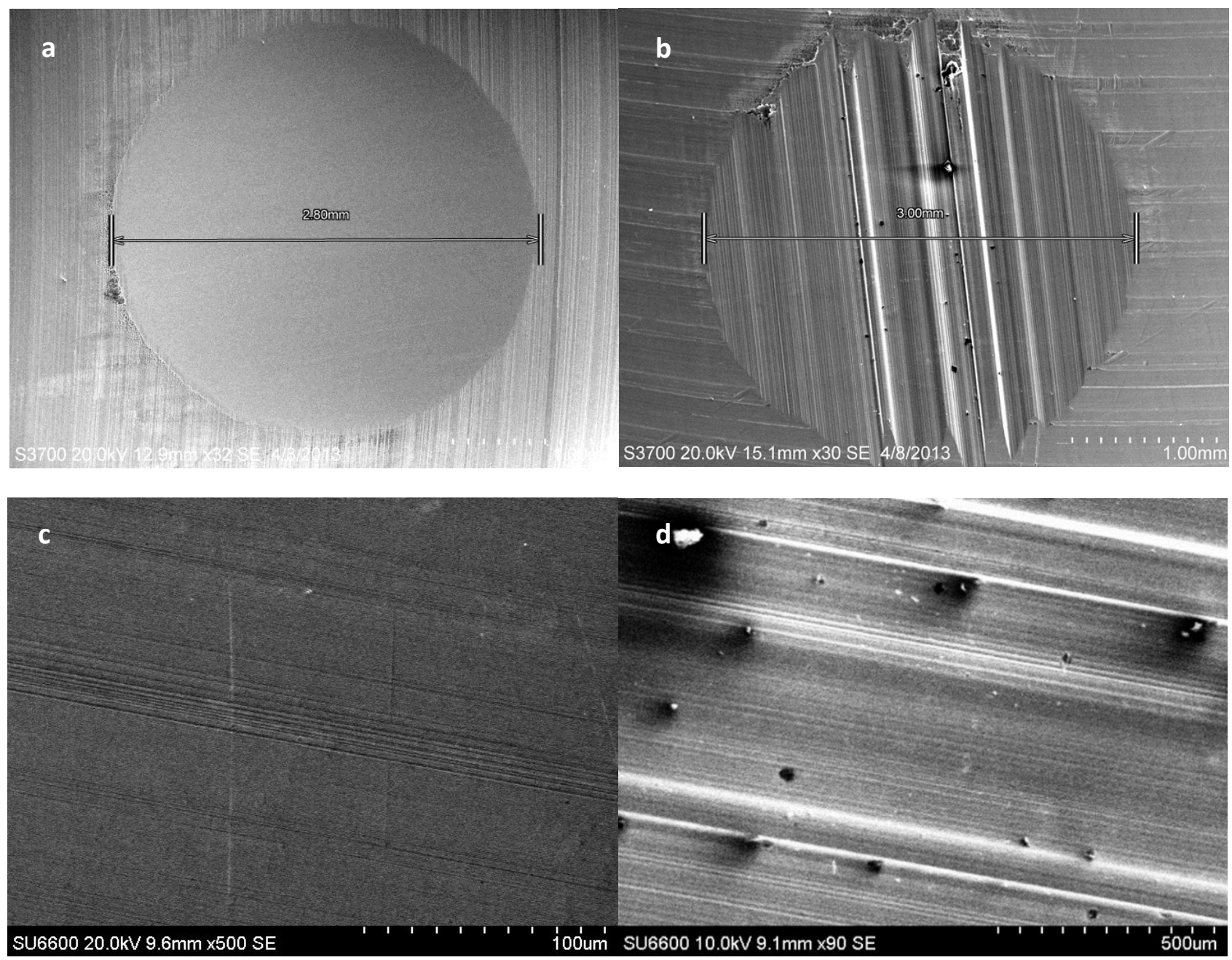

Figure $5-$ SEM analysis results a) $3 \mathrm{~h}$ test with $0.5 \mathrm{~N}, \mathrm{~b}$ ) $3 \mathrm{~h}$ test with $4 \mathrm{~N}, \mathrm{c}$ ) $3 \mathrm{~h}$ test with $2 \mathrm{~N}$, d) $3 \mathrm{~h}$ test with $4 \mathrm{~N}$

\subsection{Wear maps}

Wear maps have been constructed for dental materials and can be useful in order to compare the results in a visual manner. From the result of the wear scar measurements, wear maps were produced. Wear maps allow the amount of wear that has occurred under the various conditions to be expressed in a more qualitative manner.

In order to produce these wear maps, values for wear volume had to be defined as belong to three categories; low, medium and high wear. Based on previous work [42], the categories were defined as follows based the maximum wear volume produced $\left(0.2505 \mathrm{~mm}^{3}\right)$ :

- High wear $\geq 80 \%$ of maximum wear $\left(0.2004 \mathrm{~mm}^{3}\right)$

- $30 \%$ of maximum $\leq$ Medium wear $<80 \%$ of maximum

- Low wear $>30 \%$ of maximum $(0.07515$ $\mathrm{mm}^{3}$ )

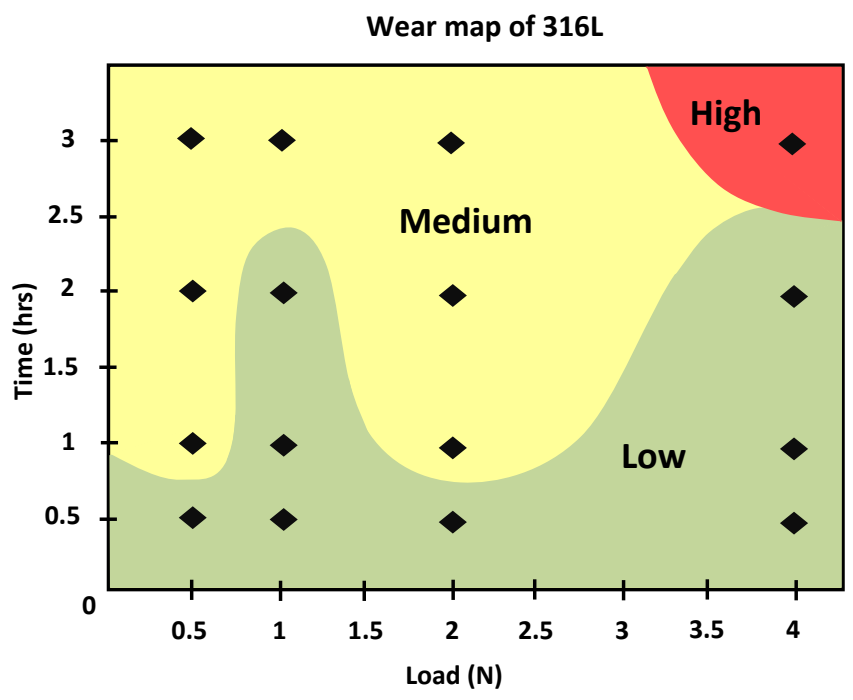

Figure 6-Wear map of SS 316L in artificial saliva 
From this, boundaries were created, the results were interpolated between these points and the maps were produced as seen figure 6 .

\section{Discussion}

In oral environments, the average tooth sliding distance has been shown to be approximately $1 \mathrm{~m}$ per day based on an average amount of chewing each day [31]. If the 316L was used as a dental crown (which receives the highest sliding distance in tooth structure), a one hour test $(897.75 \mathrm{~m}$ sliding distance) corresponds to nearly two and half years of use. This means that the tests simulates a significant period of time in the lifetime of this material and can give a good indication of the amount of wear that could potentially be experienced over this time.

Generally in metals, the predicted volume loss can be calculated using the Archard's equation for homogenous materials [43]:

$V=\frac{\kappa W L}{H}$

where $W$ is the total load applied, $H$ is the hardness of the softest contacting surface, $k$ is a dimensionless coefficient (wear coefficient) and $L$ is the sliding distance. In micro-abrasion tests, linear relationships between the wear volume and sliding distance have been generally reported for a large range of loads and slurry concentrations [31]. Therefore, wherever the results did not follow this pattern or were not as they were expected, the test has been repeated to minimise the errors which was the case for 2 and $4 \mathrm{~N}$ in this work. Since the results were reproducible, only the main results were reported for this work. According to the Archard's equation, increasing the applied load should result in a linear increase in the amount of wear produced. For steel samples, this has been shown to be true [44], up to a certain load and only under three-body conditions. Trezona et al. showed that the Archard's equation was valid for three-body rolling conditions, where wear did increase linearly with load. Also, it has been shown that when slurries with a high concentration of abrasive particles are used, wear rate is independent of applied load [37]. The results of this work exhibited the same pattern as the volume loss amounts for $0.5 \mathrm{~N}$ load showed a linear approach with increasing the sliding distance whereas for higher loads the linearity was not as clear. This can also be due to the transitions from 3-body rolling to two-body grooving as higher loads are expected to produce two-body wear which results in higher wear volumes. Another factor that can affect the effects of the applied loads is ridge formation. This is due to the contact of the ridge the rotating ball, which supports the load and results in less abrasive damage [41]. As wear rate continues to increase; particles can become trapped in ridges, causing the amount of wear to decrease. These low wear volume regions at high load can be seen in the wear map above, Fig. 6 . The instance of higher loads producing lower wear volumes suggests that ridge dominated 2-body wear has occurred. With continuing increases in applied load, it can be assumed that the ridges would be worn away, freeing the particles, resulting in a sudden increase in the wear again.

According to Archard's equation, a sliding distance should have a linear relationship with volume loss [5]. It means that increasing sliding distance should increase the volume loss. Stack and Mathew [38] has pointed out that this relationship can be more complicated than a linear relationship. This contradiction is because increasing sliding distance generally leads to an increase in the real area of 
contact and a reduction of the applied load at the interface and on the particles present at the interface. Therefore, the slope of the linear relationship may decrease due to longer sliding distances [45]. This seemed to true in the current study where the applied loads were $1 \mathrm{~N}$ or exceeded this value. It has also been reported that after long sliding times, average friction coefficient, magnitude of friction fluctuations, surface roughness, depth of deformed layer and the composition and microstructure of near surface material tend to become constant. This situation has been named as the 'steady state' [46].

One of the most important outcomes of the Archard's equation is the wear coefficient ( $\kappa$ ) which is a valuable means of comparing the severity of wear processes. It should be noted that the wear coefficient does not describe the mechanisms occurred during the wear process [47].

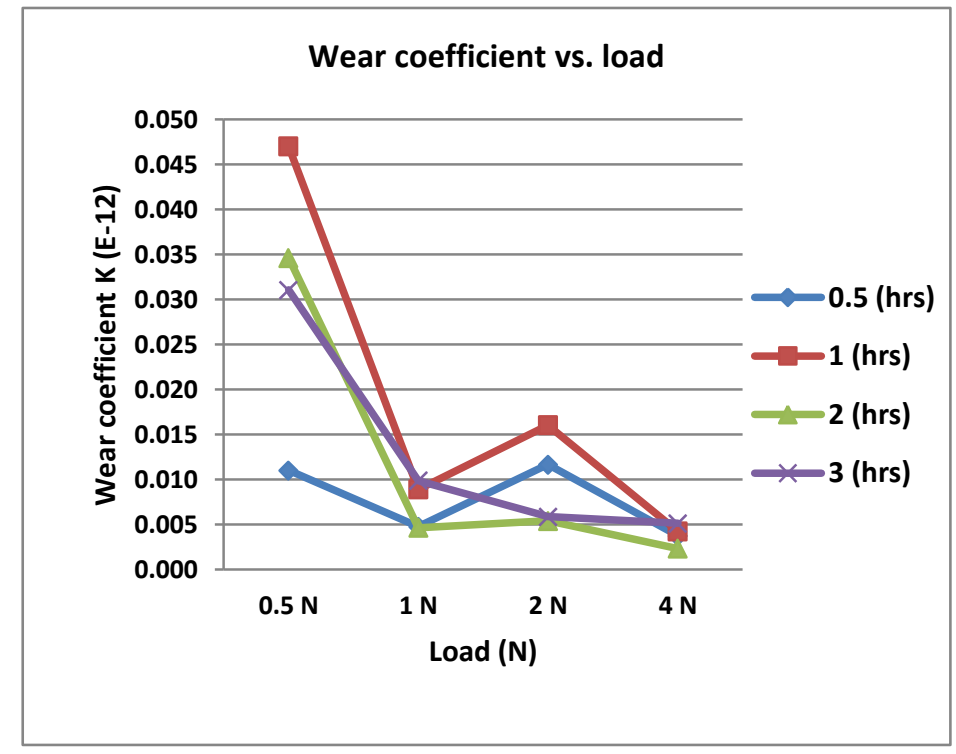

Figure 7 - Severity of wear in the tested SS 316L samples

Figure 7 indicates that by increasing the load, the severity of the wear has been decreased. This can be due to transitions from three-body to two-body grooving and ridge formations. Another reason for such conditions can be the formation of the tribo-films. The presence of the abrasive particles can alter the rate of the passivation-depassivation-repassivation at the surface of the test samples. As at higher loads the concentration of the abrasive slurry reduces at the interface due to the increased load, it is possible for the tribo-films to protect the surface and last for a longer period on time. It can also be observed in Figure 4 that the presence of the particles at the interface can increase the 'aggressivity' of the surrounding medium. Also, the differences between the corrosion potentials with and without particles indicate that the stability of the film is critically dependent on the tribological conditions in such environments.

The elements of an abrasive wear can be divided into six groups: first body, second body, interfacial elements, surrounding medium (environment), relative motion and the contact forces [40]. Although the Archard's equation is a very useful scale to examine wear incidents, additional approaches to consider the other elements such as the interfacial elements and the surrounding medium should be established to achieve more accurate wear rate predictions. The results of this work show that wear maps can be a very useful tool to provide a reference for wear predictions. This is an appropriate approach to address a worn surface qualitatively, as quantification of a wear is not always the best 
way to describe it. Quantitative reference points are also often arbitrary. The significant advantage of wear mechanism maps is that there are no limits for combining different influential factors on wear mechanisms and it can be generated regardless of the units of the factors.

Further work will be to investigate the tribo-corrosion behaviour of other relevant materials to dentistry to determine the potential of improved materials based on bio-compatibility and corrosion performance.

\section{Conclusions}

(i) A study of the effect of applied load on the micro-abrasion of stainless steel in artificial saliva has been carried out.

(ii) The results indicated that the corrosion current densities increased significantly in environments with particles.

(iii) The micro-abrasion rate showed a peak in the wear rate with increasing load; this was not found when the tests were carried out in the absence of particles.

(iv) Micro-abrasion maps have been generated based on the results showing that the severity of wear is highest in environments of high loads and exposure times, with a low wear regime identified at intermediate loads and exposure times.

\section{References}

[1] Z. R. Zhou and J. Zheng, "Tribology of dental materials: a review," J. Phys. D. Appl. Phys., vol. 41, no. 11, p. 113001, Jun. 2008.

[2] S. Sharifi, M. M. Stack, L. Stephen, W.-L. Li, and M.-C. Wang, “Micro-abrasion of Y-TZP in tea,” Wear, pp. 713-721, 2013.

[3] C. Hodge and M. M. Stack, "Tribo-corrosion mechanisms of stainless steel in soft drinks," Wear, vol. 270, no. 1-2, pp. 104-114, Dec. 2010.

[4] M. . Fathi, M. Salehi, A. Saatchi, V. Mortazavi, and S. . Moosavi, "In vitro corrosion behavior of bioceramic, metallic, and bioceramic-metallic coated stainless steel dental implants," Dent. Mater., vol. 19, no. 3, pp. 188-198, May 2003.

[5] A. Kocijan, D. K. Merl, and M. Jenko, "The corrosion behaviour of austenitic and duplex stainless steels in artificial saliva with the addition of fluoride," Corros. Sci., vol. 53, no. 2, pp. 776-783, Feb. 2011.

[6] S. Pourhashem and A. Afshar, "Double layer bioglass-silica coatings on 316L stainless steel by sol-gel method," Ceram. Int., vol. null, no. null, Jul. 2013.

[7] A. Itman Filho, J. M. D. A. Rollo, R. V. Silva, and G. Martinez, "Alternative process to manufacture austenitic-ferritic stainless steel wires," Mater. Lett., vol. 59, no. 10, pp. 1192-1194, Apr. 2005.

[8] J. F. McCabe and A. Walls, Applied Dental Materials. Wiley-Blackwell, 2008, p. 312. 
[9] A. G. Threlfall, L. Pilkington, K. M. Milsom, A. S. Blinkhorn, and M. Tickle, "General dental practitioners' views on the use of stainless steel crowns to restore primary molars.," Br. Dent. J., vol. 199, no. 7, pp. 453-5; discussion 441, Oct. 2005.

[10] G. Schmalz and D. A. Bindslev, Biocompatibility of Dental Materials. Springer, 2008, p. 380.

[11] S. Karimi, T. Nickchi, and A. M. Alfantazi, "Long-term corrosion investigation of AISI 316L, Co-28Cr$6 \mathrm{Mo}$, and Ti-6Al-4V alloys in simulated body solutions," Appl. Surf. Sci., vol. 258, no. 16, pp. 60876096, 2012.

[12] E. Sajewicz, "Effect of saliva viscosity on tribological behaviour of tooth enamel," Tribol. Int., vol. 42, no. 2, pp. 327-332, Feb. 2009.

[13] J. Gibson and J. Beeley, "Natural and synthetic saliva: a stimulating subject," Biotechnol. Genet. Eng. Rev., vol. 12, pp. 39-62, 1994.

[14] L. Wang, Y. Liu, W. Si, H. Feng, Y. Tao, and Z. Ma, "Friction and wear behaviors of dental ceramics against natural tooth enamel," J. Eur. Ceram. Soc., vol. 32, no. 11, pp. 2599-2606, Aug. 2012.

[15] H. Li and Z. R. Zhou, "Wear behaviour of human teeth in dry and artificial saliva conditions," Wear, vol. 249, no. 10-11, pp. 980-984, Nov. 2001.

[16] D. Ziskind, E. Venezia, I. Kreisman, and E. Mass, "Amalgam type, adhesive system, and storage period as influencing factors on microleakage of amalgam restorations," J. Prosthet. Dent., vol. 90, no. 3, pp. 255260, Sep. 2003.

[17] B. B. Zhang, Y. F. Zheng, and Y. Liu, "Effect of Ag on the corrosion behavior of Ti-Ag alloys in artificial saliva solutions.," Dent. Mater., vol. 25, no. 5, pp. 672-7, May 2009.

[18] C. M. A. Brett and F. Trandafir, "The corrosion of dental amalgam in artificial salivas: an electrochemical impedance study," J. Electroanal. Chem., vol. 572, no. 2, pp. 347-354, Nov. 2004.

[19] K. Elagli, M. Traisnel, and H. F. Hildebrand, "Electrochemical behaviour of titanium and dental alloys in artificial saliva," Electrochim. Acta, vol. 38, no. 13, pp. 1769-1774, Sep. 1993.

[20] J. C. M. Souza, S. L. Barbosa, E. Ariza, J.-P. Celis, and L. A. Rocha, "Simultaneous degradation by corrosion and wear of titanium in artificial saliva containing fluorides," Wear, vol. 292-293, no. null, pp. 82-88, Jul. 2012.

[21] A. C. Vieira, A. R. Ribeiro, L. A. Rocha, and J. P. Celis, "Influence of pH and corrosion inhibitors on the tribocorrosion of titanium in artificial saliva," Wear, vol. 261, no. 9, pp. 994-1001, Nov. 2006.

[22] J. Y. Wong and J. D. Bronzino, Biomaterials. CRC Press, 2007, p. 296.

[23] V. Muthukumaran, V. Selladurai, S. Nandhakumar, and M. Senthilkumar, "Experimental investigation on corrosion and hardness of ion implanted AISI 316L stainless steel," Mater. Des., vol. 31, no. 6, pp. 28132817, 2010.

[24] W. D. Callister, Materials Science and Engineering. John Wiley \& Sons, 2010, p. 1000.

[25] S. Bauer, P. Schmuki, K. von der Mark, and J. Park, "Engineering biocompatible implant surfaces," Prog. Mater. Sci., vol. 58, no. 3, pp. 261-326, 2013.

[26] K. Marcus and C. Allen, "The sliding wear of ultrahigh molecular weight polyethylene in an aqueous environment," Wear, vol. 178, no. 1, pp. 17-28, 1994. 
[27] H. Gocmez, M. Tuncer, I. Uzulmez, and O. Sahin, "Particle formation and agglomeration of an aluminazirconia powder synthesized an supercritical CO2 method," Ceram. Int., vol. 38, no. 2, pp. 1215-1219, 2012.

[28] Z. Cai, S. . Vermilyea, and W. . Brantley, "In vitro corrosion resistance of high-palladium dental casting alloys," Dent. Mater., vol. 15, no. 3, pp. 202-210, 1999.

[29] P. J. F. Roulet, P. Lambrechts, E. Debels, K. Van Landuyt, M. Peumans, and B. Van Meerbeek, "How to simulate wear?," Dent. Mater., vol. 22, no. 8, pp. 693-701, 2006.

[30] I. M. Hutchings, Tribology: Friction and Wear of Engineering Materials (Metallurgy \& Materials Science). Butterworth-Heinemann Ltd, 1992, p. 280.

[31] S. Sharifi and M. M. Stack, "A comparison of the tribological behaviour of Y-TZP in tea and coffee under micro-abrasion conditions," J. Phys. D. Appl. Phys., vol. 46, no. 40, p. 404008, Oct. 2013.

[32] G. J. . Fleming, H. S. Jandu, L. Nolan, and F. . Shaini, "The influence of alumina abrasion and cement lute on the strength of a porcelain laminate veneering material," J. Dent., vol. 32, no. 1, pp. 67-74, 2004.

[33] M. G. Gee, A. Gant, I. Hutchings, R. Bethke, K. Schiffman, K. Van Acker, S. Poulat, Y. Gachon, and J. von Stebut, "Progress towards standardisation of ball cratering," Wear, vol. 255, no. 1, pp. 1-13, 2003.

[34] R. . Trezona and I. . Hutchings, "Three-body abrasive wear testing of soft materials," Wear, vol. 233, pp. 209-221, 1999.

[35] A. M. Korsunsky, D. Dini, G. C. Sih, S. Wannasri, S. V. Panin, L. R. Ivanova, L. A. Kornienko, and S. Piriyayon, "Increasing wear resistance of UHMWPE by mechanical activation and chemical modification combined with addition of nanofibers," Procedia Eng., vol. 1, no. 1, pp. 67-70, 2009.

[36] S. Ge, S. Wang, N. Gitis, M. Vinogradov, and J. Xiao, "Wear behavior and wear debris distribution of UHMWPE against Si3N4 ball in bi-directional sliding," Wear, vol. 264, no. 7, pp. 571-578, 2008.

[37] R. I. Trezona, D. N. Allsopp, and I. M. Hutchings, "Transitions between two-body and three-body abrasive wear: influence of test conditions in the microscale abrasive wear test," Wear, vol. 225-229, no. null, pp. 205-214, Apr. 1999.

[38] M. . Stack and M. Mathew, “Micro-abrasion transitions of metallic materials," Wear, vol. 255, no. 1-6, pp. 14-22, Aug. 2003.

[39] L. M. Ramírez, E. Almanza, and L. E. Murr, "Effect of uniaxial deformation to $50 \%$ on the sensitization process in 316 stainless steel," Materials Characterization, vol. 53, no. 1. pp. 79-82, 2004.

[40] J. D. Gates, "Two-body and three-body abrasion: A critical discussion," Wear, vol. 214, no. 1, pp. 139146, Jan. 1998.

[41] M. Priest, D. Dowson, D. Sun, J. A. Wharton, and R. J. K. Wood, "Abrasive size and concentration effects on the tribo-corrosion of cast CoCrMo alloy in simulated body fluids," Tribol. Int., vol. 42, no. 11, pp. 1595-1604, 2009.

[42] H.-C. Wang, M. M. Stack, W.-L. Li, T.-F. Hong, and M.-C. Wang, “On the construction of wear maps for YTZP dental ceramics in aqueous environments: $\mathrm{pH}$, exposure time and impact angle effects," Tribol. Int., vol. 43, no. 12, pp. 2258-2267, Dec. 2010.

[43] J. F. Archard, "Contact and Rubbing of Flat Surfaces," J. Appl. Phys., vol. 24, no. 8, p. 981, Aug. 1953. 
[44] R. V. Camerini, R. B. de Souza, F. de Carli, A. S. Pereira, and N. M. Balzaretti, "Ball cratering test on ductile materials," Wear, vol. 271, no. 5-6, pp. 770-774, Jun. 2011.

[45] J. Halling, Principles of Tribology. Macmillan, 1975, p. 415.

[46] D. A. Rigney, "Comments on the sliding wear of metals," Tribology International, vol. 30, no. 5. pp. 361367, 1997.

[47] Hutchins and I. Hutchings, Tribology, Friction and Wear of Engineering Materials. Elsevier Limited, 1992, p. 284. 